\title{
SAMERNES ÄLDRE RÄTTSORDNING
}

\author{
Av Elina Helander
}

Det har gjorts få sammanfattande undersökningar om samernas rättsuppfattningar. Detta kan bero på att en rättsordning av ett förkolonialistiskt samhälle kan vara svår att studera eftersom det finns få eller inga bevarade juridiska texter eller rättsliga urkunder att gå efter. Tidigare, om ett brott hade begåtts, försonades man, men om det inte gick att återställa vänskap anlitade man egna domstolar. Dette innebär att alla brott inte kom i dagsljuset, och således är de inte dokumenterade. Det kan också vara att det inte har funnits något större intresse för samernas egna rättsregler. Skattefjällsmålet torde ha väckt ett sådant intresse åtminstone i Sverige.

Erik Solem har beskrivit utförligt samernas rättsordning i sitt klassiska verk Lappiske rettsstudier som utkom första gången 1933.

Man kan konstruera en rättsordning av ett visst samhälle på flera olika sätt. Man kan börja med att beskriva samhället: i det här fallet det samiska samhället. Hur såg samhället ut? Fanns det någon fast bosättning? Vad livnärde man sig med? Fanns det goda försörjningsmöjligheter? Vilken typ av arbetsfördelning hade man? Vad fanns det för maktprinciper? Hur var kontakten med andra folkgrupper? För det andra kan man redogöra för religionen. En tredje möjlighet är att göra jämförelser med andra primitiva folk. Det fjärde sättet är att gå igenom litteraturen och undersöka om uppgifter eller förhållanden är äldre än texterna själva. Solem poängterar vikten av att undersöka de materiella villkoren och de religiösa föreställningarna (Solem 1970 s. 2).

Jag tänkte här ange de mest utmärkande karakteristika för samernas rättsuppfattningar. Jag gör jämförelser med samiska ordspråk som jag har valt från J. Qvigstads Lappische Sprichwörter und Rätsel (1922). Nackdelen med ordspråk är att en del av dem är lånade, såsom även rättsreglerna kan vara ett lån. Det finns också andra problem med ordspråk, nämligen att deras ålder och utbredning kan vara svåra att fastslå. Jag har inte undersökt ordspråken $\mathrm{i}$ ifrågavarande hänseenden, utan jag har tagit med dem eftersom jag anser att de i sig har ett visst informationsvärde. (Siffror efter ordspråken i texten hänvisar till Qvigstads numrering).

»I de informationer man vanligen lämnar en bredare allmänhet intar de om fjällsamerna och deras flyttningar och liv i tältkåtor en mycket framträdande plats. Det har emellertid konstaterats att fjällnomadismen i sin extrema form är relativt ung som näringstyp. Den ursprungligaste typen av lapsk hushållning är nämligen jakt och fiske i kombination med hållande 
av några få tamrenar.« (Ruong 1971, s. 10 f.). Den största betydelsen vid jakt hade vildrenen som det fanns gott om i hela sameområdet ännu på 1600-talet. Vildrenstammen började emellertid minska kraftigt på 1700talet. $\mathrm{M}$ an hade några få tamrenar som användes delvis som lockdjur och delvis som dragdjur. Uppgifter från 890-talet visar att samerna använde tamrenen på detta sätt. Sålunda berättade den norske hövdingen Ottar, som bodde i nuvarande Tromsö fylke, för den engelske kungen Alfred att han hade sex hundra tama renar, av dessa 6 lockrenar. Tamrenen användes alltså ursprungligen vid jakt som bruksdjur till skillnad från renens senare användning som produktionsdjur. När renen började användas som produktionsdjur var de tama renflockarna inte speciellt stora i början: det rörde sig om några tiotal renar. Utvecklingen från den ursprungliga samiska hushållningen, ärjemarkskulturen, skedde på olika sätt i olika områden.

Det samiska samhället hade, innan det kom i beröring med storsamhällena, en karaktär av någon slags kollektivism. Det var siida, samebyn, som var ägare av all mark och vatten. Arbetet, storjakt och storfiske, utfördes kollektivt och bytet delades gemensamt. Man tog samfällt hand om de sjuka och fattiga. Beträffande skoltsamernas samhälle anser Solem att det var frăga om en art av kommunism (jfr. Solem 1970, s. 100).

Samernas bosättningsområde kan indelas i flera skilda geografiska områden. Och när man talar om samerna, brukar man indela dem i skogs-, fjäll- och sjösamer. Samernas samhällen och motsvarande rättsregler har i princip varit lika överallt i hela sameområdet.

Skoltsamerna i öst (i dag finns omkr. 500 östsamer i Finland och 2000 i Ryssland) har bevarat den gamla samhällsordningen till våra dagar. »På en fascinerende måte ble vi brakt inn $\mathrm{i}$ en sosial og menneskelig trygghet som var preget av fellesskap og likeverd, og hvor det aldri eksisterte generasjonsproblemer i ordets moderne forstand. Her smeltet slektleddene sammen $i$ et naturlig og miljømessig fellesskap, hvor livsvisdom, yrkesferdighet og familiefølelse ble forvaltet og formidlet videre til nye generasjoner. Livet bølget stabilt og harmonisk etter naturens jevne årsrytme, og det var preget av fjellfolkets sjelelige likevekt og flegmatiske ro. Her fant vi ingen heseblesende jakt etter ytre statussymboler som markerte en perspektivløs og umenneskelig egoisme. Naturkraftene og livet sveiset menneskene sammen i en solidaritet som gjorde de fleste trygge og lykkelige i ordenes enkleste forstand.« (Hirsti 1974, s. 16).

Det var isolationen som gjorde det möjligt för skoltsamerna att bevara sin kultur på det stadium som den hade varit i minst två tusen år. Ryssarna lämnade skoltsamer i fred: de straffades t. ex. inte för sin hedniska tro, såsom fallet var i Sverige (jfr. Nickul 1970, s. 186 f.). Vad det gäller rättsväsendet begränsade ryssarna skolternas ömsesidiga domrätt 1517 i samband med skattereformer, men det var bara de grovsta brotten som överlämnades till ryska domstolar. 
Skoltsamernas samhälle såg ut på följande sätt: varje siida (by) hade sitt geografiska område, gränserna utgjordes av älvar, fjällryggar osv. Skolterna levde huvudsakligen av fiske och jakt. Siidans område delades mellan olika släkter samtidigt som det fanns områden som var gemensamma för hela byn. Siidan ägde all jord, den kunde ta bort delar av ett släktområde och ge det till någon annan släkt. Den enskilda människan hade bruksrätt; emellertid blev det så att vissa områden tillhörde vissa släkter under flera hundra år (se Nickul 1970, s. 19). Släkten verkade förresten stå i centrum i samhällsordningen: skolterna kunde i regel räkna upp sina släktingar sex led bakåt i tiden.

Storfiske och storjakt utfördes gemensamt såsom jag redan sagt ovan. Man delade bytet så att varje familj fick sin del, även fattiga och sjuka fick en andel av bytet. Man fick jaga och fiska också som privatperson. Den som var t. ex. ute och reste fick fiska var som helst med ett par nät. I regel måste man hålla sig till släktens eller familjens områden. Om en person var ägare till fiskeredskap fick han ersättning för utnyttjandet av dem. I storjakt fick en medlem från varje familj delta. Om en vildren hade flytt till någon annans område fick man följa den, men inte dräpa den innan ägaren av området hade blivit informerad om saken: den sistnämnda fick del av bytet. Om någon sköt en vildren i en annans hjord fick hjordägaren en andel av bytet. Om en björn blev dräpt inom ett visst släktområde hade varje medlem av släkten rätt att få sin del av bytet.

Skolterna hade ett eget organ, norraz, på ryska sobor, för byns inre och yttre angelägenheter. Ordförande för bystämman hette vuaiv-olmaž, 'huvudman' eller siid-šurr 'byn store'. De äldsta i byn hade alltså den största auktoriteten, varje familj var emellertid representerad i bystämman genom husbonden. Norraz bestämde över släktområden, ändringar i ägandemärket, skatter, skulder, inflyttare osv. Norraz fungerade också som domstol där man förhandlade med andra byar om gränserna och avgjorde andra typer av rättstvister, t. ex. om någon hade begått ett brott mot de enskilda eller mot bruksrätten inom bygemenskapen.

Skolternas bystämmaordning vande byns medlemmar vid självständig förtrogenhet med administrativa och rättsliga uppgifter och uppfostrade dem i en ansvarsmedveten och social anda (Itkonen 1948, II, s. 255).

Tidigare, när alla skoltsamer var under ryskt välde, tillhörde de Aleksandrovskis distrikt i Arkangels län, som administrerades från Kola. Samerna tillhörde en egen fogdekommun, på ryska volost, vilken var delad till obstsestvos och dessa i sin tur till byar, siid på skoltsamiska, pogost på ryska. Distriktsdomstol, distriktspolismästare och fogdedomare (volostdomare) fanns i Kola. Obstsestvos och byarna höll tillsammans med ryska tjänstemän sammanträden i Kola, där man tog upp gränstvister mellan de olika byarna. Det hände sällan att man behövde hänvisa ett mål till volostdomstolen. Man begränsade de ryska tjänstemännens maktmissbruk genom att $t$. ex. minska 
deras lön eller avskeda dem vid otillåtet bruk av deras ställning. Vid Kolamötet behandlades alltså sådana ärenden som man inte kunde komma överens om på bystämman. Det ursprungliga syftet med den här administrativa modellen var att lättare kunna uppbära skatt.

Den som vill fördjupa sig ytterligare i skoltsamernas förhållanden hänvisas till den finske skoltexperten Väinö Tanners Antropogeografiska studier inom Petsamo-området. Skoltlapparnas; Fennia 49, No 4, Helsingfors 1929.

Handelsmän frán Finland, s. k. birkarlar hade delat upp samernas land mellan sig. Deras största handelsdistrikt var Kemi lappmark.

I Kemi lappmark var samarbete vid jakt bestämmande för det samhälleliga livet. Man arbetade i jaktlag. Vinterbyn var centrum för det kollektiva livet. Minskningen av vildrenar och annat vilt (bäver, mård osv.) berodde på världsmarknaderna och nybyggarverksamheten. År 1553 upptäckte engelsmän mynningen till floden Dvina, som är handelsväg till Vita Havet. Två år senare kom nederländare, sedan fransmän. För att kunna idka handel med dessa kehövde ryssarna skinn på vilket det fanns stor efterfrågan i Europa just då. Redan i början av 1600-talet klagade samerna över att viltbeståndet började minska $\mathrm{i}$ deras områden. Införandet av skjutvapnen var också ett skäl till nedgången av villebråd. Den starkaste faktorn vid nedbrytande av samekulturen i Kemi lappmark var dock kolonialisationen genom finska bönder, vilkas näringssätt, svedjebruk, undanröjde samernas näringsliv. Därtill kommer att de finska bönderna inte bara var stationära utan de gjorde också långa jakt- och fiskefärder till de områden som samerna med sedvanerätt hade utnyttjat. Den svenska statsmakten hade haft fel när den trodde på den s.k. parallellteorin som går ut på att samernas rörliga och finnarnas stationära levnadssätt skulle kunna existera bredvid varandra. För samerna fanns det $\mathrm{i}$ en sådan situation två möjligheter: dra sig undan och flytta eller byta levnadssätt (se vidare Tegengren 1952; Ruong 1971 , s. 54 ff.).

I Kemi lappmark kallades byhusbonden siida-ised eller siida-olmai. Hans auktoritet baserade sig på hans duktighet eller klokhet. Siida-ised kunde antingen ensam eller i samråd med andra bybor avgöra i tvister mellan byns medlemmar. I Kemi lappmark kallades bystämman kåta-kärreg. Alla husbönder var med, utom den som hade dåligt rykte: den sam hade fiskat olovligt i andras fiskevatten fick t. ex. inte vara med, inte heller sådana nya bymedlemmar som hade avlägsnats från sina hembyar. Det var bara samernas tvister som togs upp i kåta-kärreg. Det sista kärreg i Enare hölls på 1860 -talet.

I Sverige arbetade Karl IX på att göra samerna förtrogna med svenska rättsvanor. Han lät t. ex. bestämma fasta kyrkoplatser i olika lappmarker. »Förmodligen var det samernas gamla vinterbyar, Talvatisah (så har Jokkmokks och Arvidsjaurs kyrkplatser kallats till sen tid), som blev de fasta 
punkter där kronan, kyrkan och domarna kom att ha de direkta förbindelserna med samerna.« (Ruong 1975, s. 385; se även Schefferus 1965, s. 195 f.). Det var egentligen Gustav Vasa som på allvar startade koloniseringen i norr. Han begränsade birkarlarnas makt och ersatte dem med kungliga fogdar.

Beträffande samernas samhällsorganisation menar Ruong (1971, s. 44) att »i Sverige har också förekommit bysamhälligheter av den typ vi finner hos östsamerna.« (Se vidare Itkonen 1948, II, s. 256 f.).

För rättsssystemets vidkommande säger Solem i Lappiske rettsstudier s. 98, att »fra andre lappmarker foreligger det så vidt jeg har sett ikke oplysninger om lappting med en større kollegial rett i likhet med den skoltelappiske norraz. Men vi har oplysninger om at lappene innbyrdes hadde dommere som avgjorde deres tvister.«

Att man hade ett kollektivt näringsliv krävde att den enskilda visade stor lojalitet mot samhället. Jag har redan ovan nämnt att byn var indelad i släktområden. Släkten utövade en stor makt över den enskilda människan, den sistnämnda var rättssubjekt bara i egenskap av medlem i en släkt. På 1600-talet bodde skoltsamerna i mycket stora familjer. En familj kunde bestå av flera generationer, så att husbonden bodde tillsammans med sina gifta barn och gifta barnbarn. En husbonde hade en obegränsad makt: Han var ledamot i bystämman och hemma bestämde han över allting. Han var också ägare till sina närsläktades egendom utom gåvor (Itkonen 1948, II, s. 277).

Förutsättningen för att ett sådant samhälle skulle fungera var att alla arbetade hårt. Möjligheten att samarbetet kunde rubbas var en mäktig faktor som befrämjade konformitet och lojalitet. Om någon inte tog del i fångsten fick han ingen del i bytet. Eftersom försörjningsmöjligheterna var goda och släktområdena tillräckligt stora så fanns det inga större anledningar till hårda beteendemönster. I samma takt som viltet tog slut, nybyggarverksamheten ökade, renflockarna blev större och områdena krympte, blev mentaliteten hårdare och brottsliga handlingar ökade.

Nedan skall jag ta upp några ordspråk från Qvigstad som ger uttryck för kollektivitet och visar arbetets centrala betydelse.

- Ale ane alla jurddagid jecad harrai (7). Du skall inte ha höga tankar om dig själv.

- Gal naelggi gocco barggat vel laikes olbmu nai (201 a). Hunger befaller även den lata människan att arbeta.

- Alkke barggamest ja alkke maidai borramest (26). Den som har lätt med arbete har även lätt med mat.

- Goikke julgigun i fidne oktage gulid (256). Med torra fötter får du ingen fisk. 
- Gaega i boade mikkege (310). Genom att endast ha avsikter blir ingenting gjort.

- I daina aele atte gussid njalbmai gaeccat (339). Man lever inte av att titta på gästernas mun.

En slags harmoni var en nödvändighet i det tidiga samhället. Samhället var välvilligt mot den enskilda individen och denna i sin tur var lojal mot andra, mot samhället. Det hade utvecklats normer och sanktioner vilkas uppgift var att skydda samhället och de enskilda mot inre och yttre fiender. Där fanns inget utrymme för det individuella självintresset. Man hade ett annat människoideal: man skulle vara arbetsam, pålitlig och lugn.

Följande ordspråk skall ytterligare belysa detta:

- Barggo dakkis ramida (50). Arbetet adlar mannen.

- Ale hala, amas dak rabas baeljek gullat (16). Tala inte högt för att de lyssnande öronen inte hör dig.

- Ale gale baddjel ruoddjasit, amas njuosskat (14). Vada inte över skorna så att du inte blir våt.

- Bahas saervvevuotta billista buore olmmu, ja buorre saervvevuotta lae baeivalas laibbi (43). Dåligt sällskap fördärvar en god människa, bra sällskap har dagligt bröd med sig.

- Buorre guoimme oanida ollo madki (77). Gott sällskap gör vägen mycket kortare.

- Dalkke buorran, mutto i bahas olmus (96). Vädret blir bättre, men inte en dålig människa.

Hittills har det endast varit tal om samhället. Innan jag går över till brott och straff tänker jag berätta något om ägandeförhållanden.

Til lösöre hade samerna privaträtt. Det är alltså fråga om personliga bruksföremål och bearbetade saker (jfr. Solem 1970, s. 254). Itkonen berättar att speciellt renar, renhudar, skinn och fåglar var i mannens ägo; en kvinna däremot ägde kläder, skoband, skohö, sytillbehör osv. Tidigare var husbondens makt enligt Itkonen (se ovan) så stor att nästan alla familjens ägodelar var i hans besittning. Familjens egendom märktes med husbondens ägandemärke. Sedermera blev emellertid den enskildas äganderätt utvidgad. (Se Itkonen 1948, II, s. 277). Allting verkar tyda på att samerna hade också en annan typ av lös egendom som jag kallar idéell egendom. Det är sålunda fråga om gudaväsen, skyddsandar, trolldomskonster och andliga sånger. Forntida tro har haft sin betydelse till våra dagar, och därför anser jag det viktigt atl ägna några rader åt den. Sieidi är ett slags gud som varje familj och by, och även den enskilda, hade i sin ägo. En sådan sieidi-gud bevarades ibland hemma som skydd mot tjuvar (Ibid., s. 314). Sieidi-gudarna, ofta gjorda av sten eller trä, uppfattades som levande. Således straffade man ibland dessa om de inte var plikttrogna (Ibid., s. 319). En annan art av idéell egendom var skyddsandarna. Skoltsamerna hade uppfattningen att 
dessa andar kunde ärvas från far till son och från mor till dotter. De kunde användas för att skada andra människor. Nåjden spelade en väsentlig roll i det forna samiska samhället: man kunde vända sig till honom om man t. ex. ville veta hur man straffar en människa som begått ett brott, men då gällde det att ha en exakt kännedom om vem som var skyldig. (Ibid., s. 345). Itkonen ger uttryck för uppfattningen att även nåjdkonsten gick i arv från far till son. Den fjärde kategorin av idéell egendom är andliga sånger som man fick från »spådoms anda" (se Schefferus 1956, s. 153).

Vad det gäller lösöre gör man skillnad mellan död och levande egendom. Tamrenhushåll i sin extrema form är en ganska sen företeelse. I Sverige var det på 1600-talet, då renbeståndet började minska, som det samiska hushållet började utvecklas till ett hushåll med stora renflocker. Hos skoltsamerna var det först vid sekelskiftet $(1800 / 1900)$ som man började äga stora privata hjordar. Den stora renhjorden gav dess ägare anseende och makt, fast fördelarna i det dagliga livet var få: „Fastän han kan vara rik, får han ändå ofta svälta, ty på de vida fjellen aflägsnas han ofta längre, än han hade ämnat, och kommer icke hem, så fort han beräknat.« (Laestadius 1831, s. 227). Sidan 229 i samma bok berättar Laestadius om skillnader i rikedom mellan skogs- och fjällsamer i trakterna omkring Arvidsjaur i Sverige. Han menar att fjällsamerna hade en större renhjord och mera silverprydnader, men mindre lösöre än skogssamerna. I och med renskötselns utveckling blev det en slags ståndsskillnad bland samerna. Speciellt inom den renskötande gruppen fanns det skillnader i rikedom (Jfr. Itkonen 1948, II, s. 280). Beträffande ägandeförhållanden omkring renen i övrigt, se Solem 1970, s. 254 och Itkonen 1948, II, s. 277 ff.

Rikedomens betydelse kommer fram i följande ordspråk:

- Gal rutta bajida olmma (684). Nog upphöjer pengarna mannen.

- Gal riggas namma gukkas gullu (203). Den rikas namn hörs långt.

- Evri mieldde maidai rutta boatta (167). Pengarna kommer öre för öre.

- Rutta lae dego fuorra; golgga olbmus olbmui (662). Pengarna liknar en hora; de vandrar från en människa till en annan.

Den allmänna uppfattningen i fråga om samernas jordägandeförhållanden synes vara att det var ursprungligen samebyn som var ägare av all mark och vatten; den enskilde hade enbart bruksrätt (se t. ex. Ruong 1971, s. 58). Såsom ovan sagts var det siidan (byn) hos skolterna som ägde byns marker, och norraz (bystämman) hade rådigheten över desamma. Siidan delade sitt område mellan olika släkter; emellertid fanns det också gemensamma områden till vilka alla inom byn hade utnyttjanderätt (se Nickul 1970, s. 20; jfr. Laestadius 1833 , s. 303).

Enskilda familjer kunde ha jord och vatten i privat ägo inom släktområdet. Sålunda finns det uppgifter från 1600- och 1700-talen avseende några byar i Kemi lappmark om existens av privata jakt- och fiskeområden (jfr. 
Itkonen 1948, II, s. 256). Petrus Laestadius skriver i Fortsättning av Journalen (1833, s. 300) att »ingenting är naturligare, än att hela Byns område vore ett gemensamt betesland för samtelige Byamännen. Så lärer förhållandet också ännu vara i de Nordligaste Lappmarkerna, och så har det, efter all sannolikhet, fordom varit i de sydligare äfven.« $\mathrm{På}$ nästa sida fortsätter han: »Men ehuruväl nu Byn samfäldt rådde om sitt Renbetes-land, såsom den samfäldt skulle ansvara för skatten, så ansågos dock vissa trakter vara hvars och ens enskilda tillhörigheter.« Vidare fortsätter han: »så är hans egande rätt större ju närmare det är omkring kåtan, men blir svagare ju längre det bär derifrån«.

I Sverige fanns alltså tidigare byar av den typ som hos skoltsamerna. Redan i mitten av 1500-talet använde enskilda samer eller släkter vissa områden med sedvanerätt. Sådana områden kunde ärvas. Rätten till dem stadfästes i början av en svensk domstol, häradsrätten. Men senare skedde erkännandet genom landshövdingen, vilket medförde en uppfattning om att markerna är kronans egendom (Ruong 1971, s. 60). Redan på 1300-talet hade kronan överhöghet över samernas land. Kronans inställning på 1500och 1600-talen i fråga om jordägandet i norr var att markerna skulle stå öppna för alla. "Att dessa vidder skulle stå öppna för alla betydde dock inte att samerna stod rättslösa. Den lapska uppfattningen gjorde sig också trots allt gällande, ty vid domstolarna i lappmarken satt först nästan bara samer som nämndemän«. (Ibid. s. 58). Speciellt i början garanterade kronan samernas jakträtt, och skyddade de områden där de bodde.

Flera författare bl. a. Schefferus (1956, s. 76, 195), von Düben (1977, s. 189) och Itkonen (1948, II, s. 293) hävdar att stölder och grova brott är ovanliga hos samerna. Von Düben t. ex. säger att »ärlighet är en af deras högsta dygder, må hända der före, att hon är en absolut nödvändighet för de vandrande Lapparne. « Man måste dock hålla i minnet att alla aggressiva handlingar inte kom fram eftersom man antingen försonades sinsemellan eller anlitade egna rättsorgan. Även religionen har spelat en viss roll för rättsbildningen. Trollkonsterna kom till användning, t. ex. då man ville skada någon (se Schefferus 1956, s. 177, 181; ltkonen 1948, II, s. 334).

Vad det gäller stölder fanns det tidigare inga skäl att stjäla eftersom det fanns gott om vilt i skogarna. Samerna var ibland tvungna att färdas långa sträckor och kunde inte ha all egendom med sig. I en sådan situation är det av allmän nytta inte stjäla. Den enskilda människan levde i ett beroendeförhållande till släkten och byn, vilket säkert också hade betydelse i sammanhanget. Att man började överträda släktområden (Itkonen 1948, II, s. 257) och miste hänsynen till bygränserna (Ibid., s. 251) skapade all slags oreda. »Lappar emellan plägar också tvist om renbetesland förorsaka mycken fiendskap.« (Laestadius 1833, s. 186).

Som bevis på den utvecklade respekten för äganderätt hos samerna fram- 
lägger Solem användningen av ägandemärket. Man kunde märka i stort sett allting: olika slags föremål, båtar, björniden, trästammar med fågelbo i osv. En speciell variation av ett ägandemärke är renmärket.

Jfr. med följande ordspråk:

- Nubbe olbmo galvvo i laek baika buorek (588). Andras egendom är inte värt någonting.

- Mi suddoin ja vaerrevuodain cokkijuvvu, dat stuorra morrasin bidggijuvvu (572). Det som med synd och falskhet samlas ihop, blir utstrött med sorg.

- Verrudat gacata vaerredakki; mutto vuoiggadlasvuotta balkesuvvu buristsivdnadusain (730). Orättvisan störtar den som begår en orätt; rättskaffenhet däremot belönas med välsignelse.

- Vaerre-uobmudat i biste (740). Olagligt förvärvad egendom varar inte länge.

Rentjuveri verkar ha varit allmänt utbrett på 1800-talet, åtminstone i svenska lappmarker. Under Laestadius tid verkar rentjuveri ha varit vanligt i Pite lappmark. Och von Düben ger en bild av att renstölder på hans tid var i avtagande i Lule- och Pite lappmarker. Hos skoltsamerna däremot ökade renstölderna först mot slutet av 1800-talet som en direkt följd av att vilt och fiske tog slut och man hade ännu inte hunnit utveckla ett tamrenhushåll med stora flockar. Förr i tiden hade man äganderätt till en sådan ren som anslöt sig till ens renflock. Om man hade en renko, och en främmande kalv kom för att dägga denna, ansåg man att den sistnämnda också var ens egendom (se vidare Itkonen, II, s. 293, 298). Sålunda var det vanligaste sättet att stjäla renar att man tillägnade sig de renar av främmande ursprung som hade anslutit sig till ens egen renflock. Solem gör gällande att samerna hade en omedveten tanke om att renarna var vilda djur, gemensamma för alla, såsom det var en gång i tiden. Även Itkonen är av samma åsikt i fråga om orsaker till renstölderna.

Petrus Laestadius härleder rentjuveri från hämnden (Laestadius 1833, s. 187). Vidare menar han att »inför domstolen gällde det att neka och fordra bevis, men på fjellet vittnade opinionen«. (Ibid., s. 191). Även om det ofta var opinionen som var avgörande, hade samerna emellertid en stor känsla för konkreta bevis (Solem 1970, s. 269). Krav på konkreta bevis gällde speciellt då man tänkte stämma någon inför rätta.

Rentjuveri betraktades inte alltid som brott; i Sverige och Norge var man rent av liberal i detta hänseende. Itkonen berättar att rika renskötare stal renar som någon slags sport, och man ansåg att ett sådant stjälande inte var skamligt. Det var inte bara renskötarna själva som stal, utan t. ex. många fattiga fiskesamer begick också sådana handlingar. Att man misstänkte någon räckte till att man själv började stjäla. Ibland uppstod enligt Laestadius ett allmänt stjälande. 
Vid tjuveri tog man följande saker till beaktande:

1. Man gjorde skillnad mellan de fattiga och de rika. De fattiga som behövde mat, fick mildare straff. Man var överhuvudtaget vänlig mot de fattiga, vilket kan bero på att rika kunde förlora sina renar på en natt. (Jfr. Gaefi doaivvo alo riggot jecas, riggis balla alo gefut jecas (305). Den fattiga hoppas jämt på att bli rik, den rike är jämt rädd för att bli fattig). Även den rike renskötaren fick ta en ren från vem han ville om vargen hade härjat $\mathrm{i}$ hans renflock och han behövde mat.

2. Man tog hänsyn till om gärningsmannen var icke-same, icke-renskötande same eller renskötande same. De brott som begicks av en icke-renskötande same (nybyggare) var de grövsta; det var oftast dessa som anmäldes till myndigheterna.

3. En viktig faktor att ta hänsyn til var om gärningsmannen tillhörde de egna (släkting, bekant, dräng). Jfr. Ussteb baettem lae losimus (709). Det svåraste är att bedra en vän.

4. Om en ren hade blivit stulen av en släkting, tog man hänsyn till, om han hade ätit upp renen eller om han hade sålt den. Den sistnämnda var mindre fördelaktigt.

5. Om tjuven hade nyttiggjort sig bytet på vettigt sätt tjänade också beaktande. Ingenting fick gå till spillo.

6. Vid rentjuveri tog man hänsyn till om tjuven hade tagit renar från en egen by, från en annan by eller från ett annat land. Renarna som tillhörde samer från ett annat land. Renarna som tillhörde samer från ett annat land betraktades ställda utanför lagen. Detta betraktelsesätt gjorde det möjligt för skoltsamerna att stjäla renar från de finska samerna.

7. Nattjuveri var mer straffbart än dagtjuveri.

8. Ort och ställe för brott hade också betydelse. Det betraktades som mera skurkaktigt om man t. ex. stal från en låst bod.

9. Vidare tog man hänsyn till om man begick en stöld för första gången eller om man redan var känd som tjuv. En mycket känd rentjuv (eller smygfiskare och smygjägare) kunde avlägsnas från bygemenskapen.

Straff hade inte ursprungligen som huvuduppgift att 'straffa' utan det var snarare fråga om försoning, återställande av vänskap mellan de inblandade. Man hade minst tre typer av straff: materiell, kroppslig och avlägsnande från bygemenskapen. Det har dock också funnits magiska straffåtgärder. Om man hade stulit döda ting, fick man i regel ge sakerna tillbaka och betala deras värde dubbelt. Man gav brännvin åt domarna. Om man hade stulit en ren, gav man skinnet tillbaka, ersatte köttet och gav brännvin åt domarna. Enligt uppgifter dömdes en rentjuv i Utsjoki i norra Finland till livstidsfängelse i slutet av 1800-talet (Itkonen 1948, II, s. 294). Det vanligaste straffet vid rentjuveri, åtminstone i svenska lappmarker, verkar ha 
varit spö (Laestadius 1833, s. 190). Itkonen berättar att i vissa fall kunde en rentjuv dömas av bybor att avtjäna sitt straff som dräng hos någon rik renskötare. Enligt Laestadius skildes rentjuvarna åt, och de fick inte vistas tillsammans. Han berättar också att man kunde begå dråp på en rentjuv.

Om man hade tillägnat sig fisk i nät eller vilt i fällor, fick man leverera det stulna tillbaka och ersätta dess värde.

Mord var ovanliga förr i tiden. Sålunda betraktades ett mord som ett mycket grovt brott; speciellt avskyvärda ansågs barndråp vara (Itkonen 1948, II, s. 280). I gamla tider, om någon hade förövat mord, dömdes han till döden (Schefferus 1956, s. 177; Itkonen 1948, II, s. 255). På Laestadius tid var kanske dråp inte alldeles ovanliga i svenska lappmarker. Några samer, som hade begått ett mord dömdes av en svensk domstol till spöstraff och fästningsarbete (Laestadius 1833, s. 195). Även barn fick lida för sina föräldrars skumma handlingar i det att de också betraktades som skurkaktiga. Ofta fick hela släkten ett dåligt rykte.

Stora förändringar i samernas närings- och samhällsliv (inkl. religionen) har ändrat människoidealet och beteendemönstret samt påverkat rättsutvecklingen. Det avgörande härvid har varit trycket från storsamhällena med förändringar i samernas försörjningsförhållanden som följd. Detta har förorsakat förändringar i samernas samhälle, vilket i sin tur har haft direkta inverkan på deras rättsordning. Det gäller således att analysera olika skikt i det jag ovan beskrivit.

\section{LITTERATUR}

Gustav von Düben, Om Lappland och Lapparne, företrädesvis de svenshe. Etnografiska studier, Óstervåla 1977. (Originalupplaga Stockholm 1873).

Reidar Hirsti, Suenjel-folket-veid veis ende, Oslo 1974.

T. I. Itkonen, Suomen Lappalaiset vuoteen 1945, II. Porvoo - Helsinki 1948.

Petrus Laestadius, Journal för första året av hans tjenstgöring såsom Missionaer $i$ Lappmarken. Stockholm 1831.

- Fortsättning af Journalen öfver missionsresor $i$ Lappmarken, innefattande åren 1828-1832, Stockholm 1833.

Karl Nickul, Saamelaiset kansana ja kansalaisina, Helsinki 1970.

J. Qvigstad, Lappische Sprichwörter und Rätsel, Kristiania 1922.

Israel Ruong, Samerna, Stockholm 1971 (Första upplagan 1969).

- Historisk âterblick rörande samerna, särtryck ur Samerna i Sverige. Betänkande av Samcutredningen. SOU $1975: 100$.

Johannes Schefferus, Lappland; Acta Lapponica VIII, Uppsala 1956.

Erik Solem, Lappiske rettsstudier, Oslo 1970. (Första upplagan 1933).

Väinö Tanner, Antropogeografiska studier inom Petsamo-området. Skoltlapparnas;

Fennia 49, No 4, Helsingfors 1929.

Helmer Tegengren, En utdöd lappkultur $i$ Kemi lappmark, Åbo 1952. 
Nedan tar jag upp sådana ordspråk som kan vara av intresse i detta sammanhang. I galga baha jakkit. ouddal go oainna (360). Man skall inte tro illa om någon innan man har sett.

Dat gaedggi njuosska, middja dassidit colggujuvvu (115). Den sten på vilken man jämt spottar blir våt.

Enggel lakkai i mate oftage aellet (166). Ingen kan leva som en ängel.

Buorre namma gullu gukkas: mutto baha namma gullu vel gukkebuidi (80). Ett bra namn hörs långt, men ett dåligt namn hörs ännu längre.

Vaivasvuotta dakka davjja dego gielestaeddjin (719). Fattigdom gör en till lögnare. Aei buok sanek caci jaege (749). Alla ord är inte vattentäta.

Dak laek guokte stuorra giellasa: gaefe ja giepman (93). Det finns två stora lögnare: den fattige och handelsmannen.

Dat lae alkki cuoppat govddis raeima nubbe olmma nakis (27). Det är lätt att skära en bred remsa från en annans skinn.

Gutte lae suola, som lae maidai gielis (287). Den som är tjuv, är också lögnare.

Suollagi buok dokkalas (687). Till tjuven duger allt.

I suola cale namas (440). Tjuven skriver inte sitt namn.

Boantta i oazo goassege nuokkasan (59). Den rike får aldrig tillräckligt.

Bada burssa i dieva goassege (47). Prästens pung blir aldrig full.

Daza vuoivas lae cappad (90). Normannens lever är svart.

Goggo lae sivva, gal daggo luodda vuttu (255). Där det finns skuld, finns också spår.

Sivalas ovdemusta gieldda (35). Den skyldiga nekar först.

I garanasa calmi cuoggo (368). Kråkan sticker inte ögonen ur en annan kråka.

I han oktage gaske su jecas suorma, dastgo dat bavcag (380). Ingen biter sig i fingret, eftersom det gör ont.

Vanhem-viste saeinek gal aei duodast maiddege (725). Väggarna i föräldrahuset vittnar ingenting.

Ovtain sanin jiermalas jecas baessta (632). Med ett ord befriar sig den kloke.

Vigehaebme sadda davjja gillat asalaza oudast (536). Den oskyldige måste ofta lida för den skyldige.

Divrest maida lae vaibmo (131). Ett djur har också ett hjärta.

Gal gaefe maksa, go nagada (192). Nog betalar den fattige när han kan. 